\title{
Familiarity breeds content: Assessing bird species popularity with culturomics
}

Ricardo A Correia, Paul R Jepson, Ana C M Malhado, Richard J Ladle

Understanding public perceptions of biodiversity is essential to ensure continued support for conservation efforts. Despite this, insights remain scarce at broader spatial scales, mostly due to a lack of adequate methods for their assessment. The emergence of new technologies with global reach and high levels of participation provide exciting new opportunities to study the public visibility of biodiversity and the factors that drive it. Here, we use a measure of internet saliency to assess the national and international visibility of species within four taxa of Brazilian birds (toucans, hummingbirds, parrots and woodpeckers), and evaluate how much of this visibility can be explained by factors associated with familiarity, aesthetic appeal and conservation interest. Our results strongly indicate that familiarity (human population within the range of a species) is the most important factor driving internet saliency within Brazil, while aesthetic appeal (body size) best explains variation in international saliency. Endemism and conservation status of a species had small, but often negative, effects on either metric of internet saliency. While further studies are needed to evaluate the relationship between internet content and the cultural visibility of different species, our results strongly indicate that internet saliency can be considered as a broad proxy of cultural interest. 
1 Full Title: Familiarity breeds content: Assessing bird species popularity with culturomics

2

3 Short Title: Culturomic bird species popularity

4

5 Ricardo A. Correia ${ }^{1,2,{ }^{*}, \text { Paul Jepson }}{ }^{2}$, Ana C. M. Malhado ${ }^{1}$, Richard J. Ladle ${ }^{1,2}$

6

$7{ }^{1}$ Institute of Biological and Health Sciences, Federal University of Alagoas, Av. Lourival Melo

8 Mota, s/n, Tabuleiro do Martins, 57072-90, Maceió, AL, Brazil

$9{ }^{2}$ School of Geography and the Environment, University of Oxford, Oxford OX1 3QY, United

10 Kingdom

11

$12 *$ Corresponding author:

13 E-mail: rahc85@gmail.com (RAC)

14

15

16

17

18

19

20

21

22

23 
24 Abstract

25 Understanding public perceptions of biodiversity is essential to ensure continued support for conservation efforts. Despite this, insights remain scarce at broader spatial scales, mostly due to

27 a lack of adequate methods for their assessment. The emergence of new technologies with global reach and high levels of participation provide exciting new opportunities to study the public visibility of biodiversity and the factors that drive it. Here, we use a measure of internet saliency to assess the national and international visibility of species within four taxa of Brazilian birds (toucans, hummingbirds, parrots and woodpeckers), and evaluate how much of this visibility can be explained by factors associated with familiarity, aesthetic appeal and conservation interest. Our results strongly indicate that familiarity (human population within the range of a species) is the most important factor driving internet saliency within Brazil, while aesthetic appeal (body size) best explains variation in international saliency. Endemism and conservation status of a species had small, but often negative, effects on either metric of internet saliency. While further studies are needed to evaluate the relationship between internet content and the cultural visibility of different species, our results strongly indicate that internet saliency can be considered as a broad proxy of cultural interest.

\section{Introduction}

Species assessments are a central component of applied conservation science. In particular the categorisation and quantification of species richness, endemism and extinction risk has shaped modern conservation institutions and the geographies of conservation action (Ladle \& Whittaker 2011). However, far less attention has been given to measuring and understanding the cultural visibility and profile of wild animals and plants. This may be explained by a combination of the 
47 influential natural science critique of conservation strategies based on popular or iconic species

48 (e.g. Andelman \& Fagan 2000; Simberloff 1998), efforts to create standardised global

49 biodiversity data based on taxon and habitat units (Bowker 2000), and data constraints that until

50 recently precluded systematic assessments of species 'culturalness' at larger geographic scales

51 (Jepson \& Ladle 2009).

52 More recently however, two emerging trends are creating an imperative to generate 53 measures of species 'culturalness'. One is the rise of functionalism as an object of analysis in 54 contemporary biodiversity and conservation science. This perspective views species as 55 assemblies of traits and seeks to understand the geographies of trait distribution across space and 56 scale (Violle et al. 2014), the role of traits in ecosystem assembly and function and the 57 implications of their loss (Cadotte et al. 2011). Secondly, the rise of natural capital and ecosystem services policy frames that are pushing conservationists and academics to restate the value of biodiversity conservation in the quantitative language of economics. Cultural services are a component of these frames and this is creating the imperative to develop metrics that capture cultural services and quality-of-life benefits (Chan et al. 2012; Dallimer et al. 2012; Daniel et al. 2012; Helm 2015; IPBES 2014; Norgaard 2010). between its phenotypic (physical appearance, size, behaviour, etc.) and biogeographic traits, and the attitudes, values and cultural framings of the publics with which it interacts (Ducarme et al. 2013; Jepson \& Barua 2015; Lorimer 2007). It is simultaneously a trait in itself and a proxy of the benefits that arise from the interactions of people and culture with species and nature. Until recently, measuring the relative public popularity of a species required extensive and resource intensive social surveys, significantly constraining systematic assessments of a wide range of 
70 species at broad geographic scales (e.g. Jepson \& Ladle 2009). The internet, with its global reach

71 and high levels of social participation, has provided new opportunities for measuring public

72 perception, visibility and interest in the environment in general (McCallum \& Bury 2013; Proulx

73 et al. 2014; Richards 2013) and species in particular (Kim et al. 2014; Roberge 2014; Żmihorski

74 et al. 2013). Such approaches have been made possible by the vast amounts of data generated

75 directly or indirectly though people's interaction with the internet and the concomitant

76 development of big data analytics (Kitchin 2014) and offer new opportunities to generate metrics

77 of biodiversity that are meaningful to politicians and publics who influence decision makers

78 (Nemesio et al. 2013; Żmihorski et al. 2013). For example, web proxies of public interest in a species include the number of times that a species name has been used as a search term (Kim et

al. 2014; Schuetz et al. 2015) or the number of web sites that mention the name of a species (Żmihorski et al. 2013). Such approaches fall into the emerging sub-discipline of culturomics, the analysis of culture through the analysis of changes in word frequencies in large bodies of texts (Michel et al. 2011).

A body of recent research has identified a set of ecological and social factors that explain the public popularity of a species, although their relative importance in different cultural settings is largely unknown. These factors tend to fall into two main groupings, familiarity and aesthetic appeal. For example, a recent study demonstrated that internet searches for 68 resident bird species in the United States were positively associated with estimates of bird population densities, i.e. people were more interested in the birds that were familiar to them (Schuetz et al. 2015). Independently of whether a species is familiar, people also have strong biases towards

91 larger (Knegtering et al. 2011; Ward et al. 1998; Żmihorski et al. 2013), more colourful (Lišková 92 \& Frynta 2013; Lišková et al. 2014), cuter (Borgi et al. 2014) and more human-like (Batt 2009) 
93 species. Finally, the perceived conservation status of a species may also influence its public

94 visibility (Clucas et al. 2008).

95 Here, we use a metric of internet salience to assess public visibility of Brazilian bird 96 species belonging to four taxa (hummingbirds, toucans, parrots and woodpeckers) within

97 Brazilian and international webpages. We then test the relative importance of factors related to 98 familiarity (range size, human population within range, occurrence in anthropogenic 99 environments), aesthetic appeal (body size) and conservation interest (endemism, endangerment) 100 in explaining public visibility.

\section{Methods}

103 We evaluated the internet saliency of 236 bird species officially occurring in Brazil (Comitê 104 Brasileiro de Registros Ornitológicos 2008) and belonging to four distinct groups: hummingbirds 105 (Family Trochilidae, $\mathrm{n}=80$ ), toucans (Family Ramphastidae, $\mathrm{n}=18$ ), parrots (Family Psittacidae, $106 \mathrm{n}=85$ ) and woodpeckers (Family Picidae, $\mathrm{n}=51$ ). These four groups were chosen because they are 107 highly visible, possess substantial within-family variability in size and other phenotypic 108 characteristics, have high species richness in Brazil and all contain species that are abundant in anthropogenic landscapes.

Internet saliency of each species was assessed by performing a web search of individual

111 species names using Google's Custom Search API. In order to assess the Brazilian and 112 international saliency of each species, we carried out two types of searches: one with Brazilian 113 (Portuguese-language) popular names for webpages hosted in Brazil and one with English-

114 language popular names for international websites. Furthermore, we restricted both searches to 115 webpages that also mentioned the term "bird" (or "ave" for Brazilian searches) in order to reduce 
116 potential biases in the cases where the species name is also commonly mentioned in non-

117 biological contexts (e.g. "toucans" have a political connotation in Brazil). The number of

118 webpages returned by the search was log-transformed and ultimately used as a metric of internet

119 saliency (Sitas et al. 2009; Żmihorski et al. 2013).

120 Additionally, we collected information related to public familiarity with the species

121 (range size, human population within species range, occurrence in anthropogenic environments),

122 aesthetic appeal (body size) and conservation interest (endemism, endangerment). Range size

123 (RAN) was calculated as the extent of the species distribution based $\left(\mathrm{km}^{2}\right)$ on BirdLife's species

124 distribution maps (BirdLife International and NatureServe 2014). Human population within the

125 species range (POP) was estimated from a gridded map of world population (Center for

126 International Earth Science Information Network \& Centro Internacional de Agricultura Tropical

127 2005) by summing the values of all the map cells that intersect the species distribution. Data on

128 species occurrence in anthropogenic environments (ANT) and body size (SIZ) was collected 129 from available bird guides (Sigrist 2014). Endemic species were identified from the list of

130 Brazilian birds published by the Comitê Brasileiro de Registros Ornitológicos (Comitê Brasileiro

131 de Registros Ornitológicos 2008) and endangered species were classified as all the species with

132 an endangerment category of Vulnerable (VU), Endangered (EN) or Critically Endangered (CR)

133 according to the IUCN Red List of Threatened Species (IUCN 2014). The full data used for

134 analysis is available in S1 Appendix. All explanatory variables were standardized prior to 135 analysis (Schielzeth 2010) and we found no evidence of severe collinearity between variables 136 (Spearman’s $r \leq|0.75|)$.

137 The relationship between familiarity, aesthetic and conservation interest variables and 138 internet saliency was assessed using Generalized Linear Models (GLMs) with Gaussian 
139 distribution and identity-link function. We implemented models independently for Brazilian and

140 international internet saliency metrics and for each individual bird group as well as for all species

141 pooled together. All possible model combinations (without interactions) relating internet saliency

142 to the six explanatory variables were calculated using a multimodel inference approach

143 (Burnham \& Anderson 1998) implemented with the MuMIn package for R Software. Next, we

144 identified the best performing models according to Akaike's Information Criterion corrected for 145 sample size (AICc) and Akaike's weights (wAICc). However, because no single model clearly 146 outperformed the others $(\omega \mathrm{AICc}<0.9$ for all models and groups evaluated), we used a model 147 averaging approach to obtain averaged parameter estimates and the relative importance of each 148 explanatory variable. For this process, we considered only models with $\omega \mathrm{AICc} \geq 0.05$ as this 149 score can be interpreted as the probability that a given model is the best fit for the observed data, 150 given the candidate set of models (Burnham et al. 2011). All the analysis were implemented in R 151 Software v3.1.3 (R Core Team 2015) and figures were elaborated using the ggplot2 library 152 available for the same software package.

\section{Results}

All the species evaluated in this work had at least one webpage mention in international websites and only eight species (3\% of all species) did not show any webpage mention in Brazilian websites. The average number of webpage mentions in Brazilian webpages was highest for woodpeckers ( $\sim 72$ per species) and lowest for hummingbirds ( $\sim 32$ per species), whereas the most and least mentioned groups in international websites were respectively parrots $(\sim 1872$ web mentions per species) and hummingbirds ( $\sim 643$ web mentions per species). Internet saliency was significantly higher for international searches than for Brazilian searches (ANOVA, $F=976.8, \mathrm{p}$ 
$162<0.001$ ), but no significant difference (ANOVA, $F=1.7, \mathrm{p}=0.16$ ) was found between the

163 different bird groups in either setting (Fig. 1).

164 At the species level, the Cream-colored Woodpecker (Celeus flavus) had the highest

165 internet saliency score in Brazilian searches whereas for international searches the highest score

166 was obtained by the Scarlet Macaw (Ara macao). Only the Tocu Toucan (Ramphastos toco) had

167 the highest saliency for both Brazilian and international searches within its group; the most

168 salient species differed between searches for all the other bird groups (Table 1).

169 The analysis of AICc scores and Akaike weights revealed that intercept-only models were

170 implausible when compared with the best models ( $\triangle \mathrm{AICc} \geq 14$ ), indicating some of the

171 predictors analysed clearly contributed to explain the variability in internet saliency between

172 species. However, no single model is a clear best fit for the data; rather, there are several

173 competing models with good explanatory power of both Brazilian and international internet

174 saliency (Table 2 and 3, respectively).

175 Model averaging indicated that human population within the species range, presence in

176 anthropogenic habitats, body size and endemism were important predictors of overall bird

177 internet saliency in Brazil (Relative importance $=1,00$ ). All these predictors related positively

178 with internet saliency but human population within the species range showed the largest effect

179 size for all bird groups (Table 4). In contrast, the importance of body size and presence in 180 anthropogenic differed greatly between bird groups; presence in anthropogenic habitats had a 181 greater effect size on hummingbirds and woodpeckers while the effect of body size was more 182 important for toucans and parrots. The remaining predictors, endangerment status (Relative 183 importance $=0.42$ ) and range size (Relative importance $=0.29)$, were also included in some 184 models and had a positive but negligible effect on internet saliency. 
For international saliency, body size, endemism, presence in anthropogenic habitats and

186

187

188

189

190

191

192

193

194

195

196

197

198

199

200

201

202

203

204

205

206

207

range size were all important predictors of overall international internet saliency (Relative importance $=1.00$ ). While body size showed the highest effect when all species were considered together in the models, it was only marginally higher than that of endemism and presence in anthropogenic habitats (Table 4). Also, the importance of these variables changed when bird groups were analysed individually; body size was particularly important for toucans, parrots and woodpeckers, range size was important for hummingbirds and endemism was important for woodpeckers. Again, most of these predictors related positively with internet saliency with the clear exception of endemism, which showed a consistent negative relationship. Human population within the species range (Relative importance $=0.35$ ) and endangerment status (Relative importance $=0.26$ ) had very little importance overall internet saliency and, when included in the top models, they generally showed a negligible effect.

\section{Discussion}

The internet salience of different bird species varied widely, with a few species being characterized by very high saliency (in Brazilian or international web pages) and the majority of species having low saliency. Such a log-normal distribution is unsurprising and probably reflects the limited number of species that have a public profile that goes beyond their conservation or ecological status. A more detailed analysis of the most salient species suggests that these birds are often kept as pets or have, for some reason, become part of popular culture (nationally or internationally). For example, in Brazilian web-sites, two of the most salient parrot species

(Guaruba guarouba, Amazona pretrei) are highly sought after cage birds in Brazil (Nobrega Alves et al. 2013). Another example is the Cream-colored Woodpecker (Celeus flavus), which 
208 was the most salient woodpecker in Brazilian web-sites. This species gives name to a classic

209 children's book series (Sítio do Picapau Amarelo) written by Monteiro Lobato that was later

210 adapted for theatre and television. In contrast, the three most salient parrots on international

211 websites (Ara macao, Anodorhynchus hyacinthinus, Ara ararauna) are very large, impressive

212 and colourful macaws commonly exhibited in zoos internationally and with considerable

213 ecotourism appeal. There is long history of procurement and fascination of western bird

214 collectors with such colourful species (Boehrer 2010; Watson et al. 2015), and our results

215 suggest that human interest in these species is still very high. It is also interesting to note that the

216 ecologically extinct Spix's Macaw (Cyanopsitta spixii) has a higher saliency in international web

217 sites, possibly because of its status as a global conservation icon (Juniper 2004) and as

218 inspiration for the central characters in the recent animated movies Rio and Rio 2 (Yong et al. 219 2011).

220 As might be anticipated, factors associated with familiarity (as measured by potential for 221 personal encounters) were associated with higher saliency in Brazilian websites. Specifically, the

222 human population within the range of a species seems to be the most important variable 223 explaining internet saliency, although species presence in anthropogenic habitats was also an 224 important predictor. This is true for each group individually and for all four taxa when analysed 225 together. Our findings support the importance of local familiarity in determining popularity or 226 awareness of bird species and are also concordant with studies of internet search behaviour 227 (Schuetz et al. 2015). Such concordance of findings also suggests that internet content 228 production and search behaviour may be driven by similar socio-cultural factors.

In contrast, the main driver of the overall internet saliency of Brazilian bird species in 230 international websites was body size. Although the importance of body size was lower when bird 
231 groups comprised of relatively small species with little variation in size (e.g. Hummingbirds and

232 Woodpeckers) were considered individually, its importance was also evident when all bird

233 species were evaluated together. This strongly suggests that in the absence of direct experience,

234 preferences or awareness of particular species is influenced by phenotypic characteristics. Body

235 size has previously been demonstrated to influence internet saliency of bird species (Żmihorski

236 et al. 2013) and the attractiveness of zoo animals (Frynta et al. 2013). Of course, other

237 phenotypic characteristics (e.g. colourfulness, attractiveness of song, behaviours, etc.) may be

238 even more important, but are much harder to assess in the absence of in depth social surveys. It

239 should also be mentioned that size was also significantly associated with internet saliency of bird

240 species in Brazilian web pages, although in this case it is superseded by familiarity. Interestingly,

241 presence in anthropogenic habitats was also an important predictor of international bird saliency,

242 particularly for bird groups with smaller body sizes (hummingbirds and woodpeckers). While a

243 link with familiarity, in a broader sense, is unlikely to exist, this result suggests that opportunistic

244 encounters between bird species and international visitors to Brazil may also contribute to

245 international internet saliency.

246 From a conservation perspective, the results for endemism are particularly interesting and

247 may have important implications for policy. The fact that Brazilian endemics are associated with

248 higher internet saliency strongly suggests that this characteristic provides a higher profile for

249 these species within the national setting. However, the negative association between international

250 internet saliency and endemism implies that these perceptions do not extend beyond national

251 boundaries. Raising awareness of these species within the international community may bring

252 conservation benefits, given that studies have shown that international tourists are more willing

253 to financially support the conservation of endemic species (Veríssimo et al. 2009). 
255 of bird species in Brazilian or international web pages. This is probably less a reflection of a

256 failure of the conservation movement to publicise species at risk, and more an indication of the

257 over-riding importance of familiarity (for Brazilian nationals) and phenotypic characteristics (for

258 the international community). The exceptions to these general trends are species that have

259 become global icons, such as Spix's Macaw, or which are both endangered and phenotypically

260 appealing such as the Hyacinth Macaw.

261 Overall, our findings suggest that species 'culturalness', here represented by internet

262 salience, is a relational trait that emerges from a package of species traits that afford humans

263 something. Based on this study, key species traits seem to be behavioural, dietary and/or

264 phenotypic traits that afford a) taming and easy husbandry, b) close and/or regular viewing of the

265 species during the everyday lives of 'general' publics, c) a sense of awe, wonder and/or

266 'exoticism', and d) the creation of animal characters in stories. Nevertheless, it should be noted

267 that other taxa may possess or exhibit traits that generate negative perceptions that may

268 contribute to their visibility, such as ferocious behaviour, venomous or poisonous attributes and

269 invasive characteristics. From a conservation perspective, the sentiment associated with a species

270 (positive or negative) is probably as relevant as its cultural salience (high or low visibility within

271 a cultural context). For example, $\mathrm{Xu}$ and colleagues showed that perceptions towards wolves

272 tend to be negative in Tibet, despite generally positive views about nature conservation in

273 Tibetan society (Xu et al. 2015). Even when a species has cultural visibility and is positively

274 perceived, other deeply ingrained cultural practices such as hunting may undermine its

275 conservation (Gama et al. 2016). These examples clearly illustrate some of the implications that

276 cultural perceptions can have on the success of conservation policies and actions. 

species interactions with culture. Although the culturomic techniques presented here only addresses a single dimension, our work demonstrates the potential of new digital techniques for

280 investigating these complex interactions. Future research in these areas will benefit from an 281 increased collaboration and engagement with social scientists (Ehrlich 2002), the digital 282 humanities and computer scientists working in the emerging fields of natural language 283 processing and text sentiment analysis (Wagner-Pacifici et al. 2015).

\section{Conclusions}

Assessing and understanding internet saliency of biodiversity components is important because it can be thought of as a broad proxy of cultural visibility, incorporating elements of cultural identity, heritage, spiritual significance, inspiration and aesthetic appreciation, recreation, and tourism (Dallimer et al. 2014). These elements are harder to systematically and directly quantify than more tangible biodiversity values (e.g. economic value), but play a key role in conservation efforts (Prokop \& Fančovičová 2013; Żmihorski et al. 2013). This is because, in general, people are more likely to support conservation of a species (and other components of the natural world) with characteristics that they value (Prokop \& Fančovičová 2013).

This study represents one of the first attempts to capture and understand the cultural value culture (Gere 2008), there is immense potential to expand the application of digital tools to conservation science, for example to support conservation prioritisation and planning, valuation of cultural ecosystem services, and the development of trait-based ecology. In contrast to 
300 culturomic approaches once developed can be semi-automated enabling assessments of at finer

301 temporal and spatial resolutions. This would potentially enable conservation science to more

302 effective respond to public opinion and thereby strengthen its democratic legitimacy. However,

303 more studies are needed to convincingly demonstrate the connections between internet content 304 and the behaviour of internet users and cultural values.

\section{References}

307

Andelman SJ, and Fagan WF. 2000. Umbrellas and flagships: efficient conservation surrogates or expensive mistakes? Proceedings of the National Academy of Sciences 97:5954-5959.

Batt S. 2009. Human attitudes towards animals in relation to species similarity to humans: a multivariate approach. Bioscience Horizons 2:180-190.

BirdLife International and NatureServe. 2014. Bird Species Distribution Maps of the World.

Boehrer BT. 2010. Parrot Culture: Our 2500-Year-Long Fascination with the World's Most Talkative Bird. Philadelphia, USA: University of Pennsylvania Press.

Borgi M, Cogliati-Dezza I, Brelsford V, Meints K, and Cirulli F. 2014. Baby schema in human and animal faces induces cuteness perception and gaze allocation in children. Frontiers in psychology 5:1-12.

Bowker GC. 2000. Biodiversity datadiversity. Social studies of science 30:643-683.

Burnham KP, and Anderson DR. 1998. Model selection and multimodel inference. NY, USA: Springer.

Burnham KP, Anderson DR, and Huyvaert KP. 2011. AIC model selection and multimodel inference in behavioral ecology: some background, observations, and comparisons. Behavioral Ecology and Sociobiology 65:23-35. 
323 Cadotte MW, Carscadden K, and Mirotchnick N. 2011. Beyond species: functional diversity and

324

325

326

327

328

329

330

331

332

333

334

335

336

337

338

339

340

341

342

343 the maintenance of ecological processes and services. Journal of Applied Ecology

48:1079-1087. 10.1111/j.1365-2664.2011.02048.x

Center for International Earth Science Information Network, and Centro Internacional de Agricultura Tropical. 2005. Population Density Grid. Gridded Population of the World, Version 3 (GPWv3). Palisades, NY: NASA Socioeconomic Data and Applications Center (SEDAC).

Chan KM, Guerry AD, Balvanera P, Klain S, Satterfield T, Basurto X, Bostrom A, Chuenpagdee R, Gould R, and Halpern BS. 2012. Where are cultural and social in ecosystem services? A framework for constructive engagement. BioScience 62:744-756.

Clucas B, McHugh K, and Caro T. 2008. Flagship species on covers of US conservation and nature magazines. Biodiversity and Conservation 17:1517-1528.

Comitê Brasileiro de Registros Ornitológicos. 2008. Listas das aves do Brasil. Versão 05/10/2008. Available at http://www.cbro.org.br/ (accessed 10 November 2014).

Dallimer M, Irvine KN, Skinner AM, Davies ZG, Rouquette JR, Maltby LL, Warren PH, Armsworth PR, and Gaston KJ. 2012. Biodiversity and the feel-good factor: understanding associations between self-reported human well-being and species richness. BioScience 62:47-55.

Dallimer M, Tinch D, Hanley N, Irvine KN, Rouquette JR, Warren PH, Maltby L, Gaston KJ, and Armsworth PR. 2014. Quantifying preferences for the natural world using monetary and nonmonetary assessments of value. Conservation Biology 28:404-413. 
344 Daniel TC, Muhar A, Arnberger A, Aznar O, Boyd JW, Chan KM, Costanza R, Elmqvist T, Flint

345 CG, and Gobster PH. 2012. Contributions of cultural services to the ecosystem services agenda. Proceedings of the National Academy of Sciences 109:8812-8819.

347 Ducarme F, Luque GM, and Courchamp F. 2013. What are "charismatic species” for conservation biologists. BioSciences Master Reviews 10:1-8.

Ehrlich PR. 2002. Human natures, nature conservation, and environmental ethics. Bioscience 52:31-43.

Frynta D, Šimková O, Lišková S, and Landová E. 2013. Mammalian collection on Noah's ark: the effects of beauty, brain and body size. PloS one 8:e63110.

Gere C. 2008. Digital Culture. London, UK: Reaktion Books.

Helm D. 2015. Natural Capital: Valuing the Planet. London, UK: Yale University Press.

IPBES. 2014. Preliminary guide regarding diverse conceptualization of multiple values of nature and its benefits, including biodiversity and ecosystem functions and services. Bonn:

IUCN. 2014. The IUCN Red List of Threatened Species. Version 2014.3. Available at http://www.iucnredlist.org (accessed 17 November 2014).

Jepson P, and Barua M. 2015. A Theory of Flagship Species Action Conservation \& Society 12.

Jepson P, and Ladle RJ. 2009. Governing bird-keeping in Java and Bali: evidence from a household survey. Oryx 43:364-374.

Juniper T. 2004. Spix's Macaw: the race to save the world's rarest bird: Simon and Schuster. 
367 Kim JY, Do Y, Im R-Y, Kim G-Y, and Joo G-J. 2014. Use of large web-based data to identify 368 public interest and trends related to endangered species. Biodiversity and Conservation 23:2961-2984.

370

371

372 373

Kitchin R. 2014. Big Data, new epistemologies and paradigm shifts. Big Data \& Society $1: 2053951714528481$.

Knegtering E, van der Windt HJ, and Schoot Uiterkamp AJ. 2011. Public decisions on animal species: does body size matter? Environmental Conservation 38:28-36.

Ladle RJ, and Whittaker RJ. 2011. Conservation Biogeography. Oxford: John Wiley \& Sons.

Lišková S, and Frynta D. 2013. What Determines Bird Beauty in Human Eyes? Anthrozoos: A Multidisciplinary Journal of The Interactions of People \& Animals 26:27-41.

Lišková S, Landová E, and Frynta D. 2014. Human preferences for colorful birds: Vivid colors or pattern? Evolutionary psychology: an international journal of evolutionary approaches to psychology and behavior 13:339-359.

Lorimer J. 2007. Nonhuman charisma. Environment and Planning D 25:911-932.

McCallum ML, and Bury GW. 2013. Google search patterns suggest declining interest in the environment. Biodiversity and Conservation 22:1355-1367.

Michel J-B, Shen YK, Aiden AP, Veres A, Gray MK, Pickett JP, Hoiberg D, Clancy D, Norvig P, and Orwant J. 2011. Quantitative analysis of culture using millions of digitized books. Science 331:176-182.

Nemesio A, Seixas DP, and Vasconcelos HL. 2013. The public perception of animal diversity: what do postage stamps tell us? Frontiers in Ecology and the Environment 11:9-10. 10.1890/13.wb.001 
389 Nobrega Alves RR, De Farias Lima JR, and Araujo HFP. 2013. The live bird trade in Brazil and 390 its conservation implications: an overview. Bird Conservation International 23:53-65.

391 Norgaard RB. 2010. Ecosystem services: From eye-opening metaphor to complexity blinder. 392 Ecological Economics 69:1219-1227. 10.1016/j.ecolecon.2009.11.009

393 Prokop P, and Fančovičová J. 2013. Does colour matter? The influence of animal warning 394 395 coloration on human emotions and willingness to protect them. Animal Conservation 16:458-466. 10.1111/acv.12014 Conservation Biology 28:44-51.

R Core Team. 2015. R: A language and environment for statistical computing. Vienna, Austria:

Proulx R, Massicotte P, and Pepino M. 2014. Googling trends in conservation biology.

400

401

402

403

404

405

406

407

408

409

410

411

R Foundation for Statistical Computing.

Richards DR. 2013. The content of historical books as an indicator of past interest in environmental issues. Biodiversity and Conservation 22:2795-2803.

Roberge J-M. 2014. Using data from online social networks in conservation science: which species engage people the most on Twitter? Biodiversity and Conservation 23:715-726. 10.1007/s10531-014-0629-2

Schielzeth H. 2010. Simple means to improve the interpretability of regression coefficients. Methods in Ecology and Evolution 1:103-113. 10.1111/j.2041-210X.2010.00012.x

Schuetz J, Soykan CU, Distler T, and Langham G. 2015. Searching for backyard birds in virtual worlds: Internet queries mirror real species distributions. Biodiversity \& Conservation 24:1147-1154.

Sigrist T. 2014. Guia de Campo Avis Brasilis - Avifauna Brasileira. São Paulo, Brasil: Avis Brasilis Editora. 
412 Simberloff D. 1998. Flagships, umbrellas, and keystones: is single-species management passé in 413 the landscape era? Biological Conservation 83:247-257.

414 Sitas N, Baillie J, and Isaac N. 2009. What are we saving? Developing a standardized approach 415 for conservation action. Animal Conservation 12:231-237.

416 Veríssimo D, Fraser I, Groombridge J, Bristol R, and MacMillan DC. 2009. Birds as tourism 417 flagship species: a case study of tropical islands. Animal Conservation 12:549-558.

418 Violle C, Reich PB, Pacala SW, Enquist BJ, and Kattge J. 2014. The emergence and promise of 419 functional biogeography. Proceedings of the National Academy of Sciences of the United States of America 111:13690-13696. 10.1073/pnas.1415442111

421

422

423

424 425

426

427

428

429

430

431

432

433 of Big Data in the social and cultural sciences. Big Data \& Society 2. $10.1177 / 2053951715613810$

Ward PI, Mosberger N, Kistler C, and Fischer O. 1998. The relationship between popularity and body size in zoo animals. Conservation Biology 12:1408-1411.

Watson AS, Plog S, Culleton BJ, Gilman PA, LeBlanc SA, Whiteley PM, Claramunt S, and Kennett DJ. 2015. Early procurement of scarlet macaws and the emergence of social complexity in Chaco Canyon, NM. Proceedings of the National Academy of Sciences 112:8238-8243.

Xu Y, Yang B, and Dou L. 2015. Local villagers' perceptions of wolves in Jiuzhaigou County, western China. Peerj 3.

Yong DL, Fam SD, and Lum S. 2011. Reel conservation: can big screen animations save tropical biodiversity. Tropical Conservation Science 4:244-253. 
434 Żmihorski M, Dziarska-Pałac J, Sparks TH, and Tryjanowski P. 2013. Ecological correlates of 435 the popularity of birds and butterflies in Internet information resources. Oikos 122:183$436 \quad 190$.

438 Supporting Information

439 S1 Appendix. Dataset of species level variables used for analysis. Dataset includes Brazilian 440 and international internet salience scores, range size, human population within the range, 441 presence in anthropogenic habitats, body size and endemic or endangered status for each 442 individual species considered for analysis.

443

444

445

446

447

448

449

450

451

452

453

454

455

456 


\section{Tables}

458 Table 1. The five most represented species for each study taxon (hummingbirds, parrots,

459 toucans, woodpeckers) on Brazilian and international web pages.

\begin{tabular}{|c|c|c|c|}
\hline Bird group & Rank & Brazilian web pages & International web pages \\
\hline \multirow[t]{6}{*}{ Hummingbirds } & 1 & $\begin{array}{l}\text { Swallow-tailed Hummingbird } \\
\text { (Eupetomena macroura) }\end{array}$ & $\begin{array}{l}\text { White-necked Jacobin } \\
\text { (Florisuga mellivora) }\end{array}$ \\
\hline & 2 & $\begin{array}{l}\text { Racket-tailed Coquette } \\
\text { (Discosura longicaudus) }\end{array}$ & $\begin{array}{l}\text { White-throated Hummingbird } \\
\text { (Leucochloris albicollis) }\end{array}$ \\
\hline & 3 & Gilded Sapphire & Tufted Coquette \\
\hline & & (Hylocharis chrysura) & (Lophornis ornatus) \\
\hline & 4 & $\begin{array}{l}\text { White-throated Hummingbird } \\
\text { (Leucochloris albicollis) }\end{array}$ & $\begin{array}{l}\text { Black-throated Mango } \\
\text { (Anthracothorax nigricollis) }\end{array}$ \\
\hline & 5 & $\begin{array}{l}\text { Black Jacobin } \\
\text { (Florisuga fusca) }\end{array}$ & $\begin{array}{l}\text { Swallow-tailed Hummingbird } \\
\text { (Eupetomena macroura) }\end{array}$ \\
\hline \multirow[t]{5}{*}{ Toucans } & 1 & $\begin{array}{l}\text { Toco Toucan } \\
\text { (Ramphastos toco) }\end{array}$ & $\begin{array}{l}\text { Toco Toucan } \\
\text { (Ramphastos toco) }\end{array}$ \\
\hline & 2 & $\begin{array}{l}\text { Channel-billed Toucan } \\
\text { (Ramphastos vitellinus) }\end{array}$ & $\begin{array}{l}\text { Channel-billed Toucan } \\
\text { (Ramphastos vitellinus) }\end{array}$ \\
\hline & 3 & $\begin{array}{l}\text { Green-billed Toucan } \\
\text { (Ramphastos dicolorus) }\end{array}$ & $\begin{array}{l}\text { Chestnut-eared Aracari } \\
\text { (Pteroglossus castanotis) }\end{array}$ \\
\hline & 4 & $\begin{array}{l}\text { Saffron Toucanet } \\
\text { (Pteroglossus bailloni) }\end{array}$ & $\begin{array}{l}\text { Saffron Toucanet } \\
\text { (Pteroglossus bailloni) }\end{array}$ \\
\hline & 5 & $\begin{array}{l}\text { Chestnut-eared Aracari } \\
\text { (Pteroglossus castanotis) }\end{array}$ & $\begin{array}{l}\text { Green Aracari } \\
\text { (Pteroglossus viridis) }\end{array}$ \\
\hline \multirow[t]{5}{*}{ Parrots } & 1 & $\begin{array}{l}\text { Golden Parakeet } \\
\text { (Guaruba guarouba) }\end{array}$ & $\begin{array}{l}\text { Scarlet Macaw } \\
(\text { Ara macao })\end{array}$ \\
\hline & 2 & $\begin{array}{l}\text { Blue-and-yellow Macaw } \\
\text { (Ara ararauna) }\end{array}$ & $\begin{array}{l}\text { Hyacinth Macaw } \\
\text { (Anodorhynchus hyacinthinus) }\end{array}$ \\
\hline & 3 & $\begin{array}{l}\text { Blue-winged Parrotlet } \\
\text { (Forpus xanthopterygius) }\end{array}$ & $\begin{array}{l}\text { Blue-and-yellow Macaw } \\
\text { (Ara ararauna) }\end{array}$ \\
\hline & 4 & $\begin{array}{l}\text { Blue-fronted Amazon } \\
\text { (Amazona aestiva) }\end{array}$ & $\begin{array}{l}\text { Monk Parakeet } \\
\text { (Myiopsitta monachus) }\end{array}$ \\
\hline & 5 & $\begin{array}{l}\text { Red-spectacled Amazon } \\
\text { (Amazona pretrei) }\end{array}$ & $\begin{array}{l}\text { Spix's Macaw } \\
\text { (Cyanopsitta spixii) }\end{array}$ \\
\hline \multirow[t]{5}{*}{ Woodpeckers } & 1 & $\begin{array}{l}\text { Cream-colored Woodpecker } \\
\text { (Celeus flavus) }\end{array}$ & $\begin{array}{l}\text { Lineated Woodpecker } \\
\text { (Dryocopus lineatus) }\end{array}$ \\
\hline & 2 & $\begin{array}{l}\text { Campo Flicker } \\
\text { (Colaptes campestres) }\end{array}$ & $\begin{array}{l}\text { White Woodpecker } \\
\text { (Melanerpes candidus) }\end{array}$ \\
\hline & 3 & $\begin{array}{l}\text { Lineated Woodpecker } \\
\text { (Dryocopus lineatus) }\end{array}$ & $\begin{array}{l}\text { Golden-olive Woodpecker } \\
\text { (Colaptes rubiginosus) }\end{array}$ \\
\hline & 4 & $\begin{array}{l}\text { Blond-creasted Woodpecker } \\
\text { (Celeus flavescens) }\end{array}$ & $\begin{array}{l}\text { Crimson-crested Woodpecker } \\
\text { (Campephilus melanoleucos) }\end{array}$ \\
\hline & 5 & $\begin{array}{l}\text { Green-barred Woodpecker } \\
\text { (Colaptes melanochloros) }\end{array}$ & $\begin{array}{l}\text { Campo Flicker } \\
\text { (Colaptes campestres) }\end{array}$ \\
\hline
\end{tabular}


462 Table 2. Ranked set of best candidate models of Brazilian internet salience.

\begin{tabular}{|c|c|c|c|c|c|c|c|c|c|c|}
\hline \multirow[t]{2}{*}{ Group } & \multirow[t]{2}{*}{ Rank } & \multicolumn{6}{|c|}{ Explanatory Variables } & \multirow[t]{2}{*}{$\mathrm{AICc}$} & \multirow[t]{2}{*}{$\triangle \mathrm{AICc}$} & \multirow[t]{2}{*}{$\omega \mathrm{AICc}$} \\
\hline & & RAN & POP & ANT & SIZ & EDM & EDG & & & \\
\hline \multirow[t]{7}{*}{ Hummingbirds } & 1 & & $X$ & $X$ & & X & & 73.83 & 0 & 0.107 \\
\hline & 2 & & $X$ & $X$ & & & & 73.93 & 0.10 & 0.102 \\
\hline & 3 & X & $X$ & $X$ & & & & 74.17 & 0.34 & 0.090 \\
\hline & 4 & X & & X & X & X & & 74.25 & 0.42 & 0.087 \\
\hline & 5 & & X & $X$ & X & & & 74.99 & 1.16 & 0.060 \\
\hline & 6 & X & $X$ & X & & X & & 75.13 & 1.31 & 0.056 \\
\hline & 7 & X & $X$ & $X$ & X & & & 75.25 & 1.43 & 0.052 \\
\hline \multirow[t]{6}{*}{ Toucans } & 1 & & $X$ & & X & & & 9.74 & 0 & 0.294 \\
\hline & 2 & & X & X & $X$ & & & 10.89 & 1.16 & 0.165 \\
\hline & 3 & & $X$ & & X & X & & 11.71 & 1.97 & 0.110 \\
\hline & 4 & & $X$ & $X$ & & & & 12.14 & 2.40 & 0.088 \\
\hline & 5 & $\mathrm{X}$ & $X$ & & $X$ & & & 13.01 & 3.28 & 0.057 \\
\hline & 6 & & X & & X & & X & 13.18 & 3.44 & 0.053 \\
\hline \multirow[t]{5}{*}{ Parrots } & 1 & & X & & X & X & & 144.25 & 0 & 0.315 \\
\hline & 2 & & $X$ & $X$ & X & X & & 145.90 & 1.65 & 0.138 \\
\hline & 3 & & X & & X & X & X & 146.11 & 1.85 & 0.125 \\
\hline & 4 & $\mathrm{X}$ & $X$ & & $X$ & $\mathrm{X}$ & & 146.33 & 2.08 & 0.111 \\
\hline & 5 & & $X$ & $X$ & $X$ & $\mathrm{X}$ & $X$ & 147.65 & 3.40 & 0.058 \\
\hline \multirow[t]{7}{*}{ Woodpeckers } & 1 & & $X$ & $X$ & $X$ & & & 67.61 & 0 & 0.213 \\
\hline & 2 & & $X$ & $X$ & $\mathrm{X}$ & $\mathrm{X}$ & & 69.16 & 1.55 & 0.098 \\
\hline & 3 & & $X$ & $X$ & & & & 69.28 & 1.66 & 0.093 \\
\hline & 4 & $X$ & $X$ & $X$ & & & & 69.34 & 1.72 & 0.090 \\
\hline & 5 & $X$ & $X$ & $X$ & $X$ & & & 69.38 & 1.77 & 0.088 \\
\hline & 6 & & $X$ & $X$ & $X$ & & $X$ & 70.15 & 2.54 & 0.060 \\
\hline & 7 & & $X$ & $X$ & & $\mathrm{X}$ & & 70.22 & 2.60 & 0.058 \\
\hline \multirow[t]{4}{*}{ All groups } & 1 & & $X$ & $X$ & $X$ & $\mathrm{X}$ & & 310.30 & 0 & 0.382 \\
\hline & 2 & & $X$ & $X$ & $X$ & $\mathrm{X}$ & $X$ & 310.97 & 0.67 & 0.274 \\
\hline & 3 & $X$ & $X$ & $X$ & $X$ & $X$ & & 312.08 & 1.78 & 0.157 \\
\hline & 4 & $\mathrm{X}$ & $X$ & $X$ & $X$ & $\mathrm{X}$ & $X$ & 312.71 & 2.41 & 0.115 \\
\hline
\end{tabular}

463

464 465

466

467

468

469

470

471

Models are ranked by order of lowest AICc score and only models with a weight over 0.05 were considered. Rank, explanatory variables, AICc score, delta AICc relative to the model with lowest AICc score and Akaike weights are given for each individual model. 
472 Table 3. Ranked set of best candidate models of international internet salience.

\begin{tabular}{|c|c|c|c|c|c|c|c|c|c|c|}
\hline \multirow[t]{2}{*}{ Group } & \multirow[t]{2}{*}{ Rank } & \multicolumn{6}{|c|}{ Explanatory Variables } & \multirow[t]{2}{*}{$\mathrm{AICc}$} & \multirow[t]{2}{*}{$\triangle \mathrm{AICc}$} & \multirow[t]{2}{*}{$\omega \mathrm{AICc}$} \\
\hline & & RAN & POP & ANT & SIZ & EDM & EDG & & & \\
\hline \multirow[t]{4}{*}{ Hummingbirds } & 1 & $\mathrm{X}$ & $\mathrm{X}$ & & & & & 1.04 & 0 & 0.080 \\
\hline & 2 & $X$ & & & & & & 1.12 & 0.07 & 0.077 \\
\hline & 3 & $X$ & $\mathrm{X}$ & & & $X$ & & 1.28 & 0.24 & 0.071 \\
\hline & 4 & $X$ & $\mathrm{X}$ & & $X$ & & & 1.96 & 0.91 & 0.051 \\
\hline \multirow[t]{5}{*}{ Toucans } & 1 & & & & $\mathrm{X}$ & & & 15.58 & 0 & 0.206 \\
\hline & 2 & & $\mathrm{X}$ & & $\mathrm{X}$ & & & 15.99 & 0.41 & 0.168 \\
\hline & 3 & & & & $\mathrm{X}$ & & $\mathrm{X}$ & 16.73 & 1.14 & 0.116 \\
\hline & 4 & & $\mathrm{X}$ & & $\mathrm{X}$ & & $\mathrm{X}$ & 17.96 & 2.38 & 0.063 \\
\hline & 5 & & & $\mathrm{X}$ & $X$ & & & 18.08 & 2.50 & 0.059 \\
\hline \multirow[t]{5}{*}{ Parrots } & 1 & $X$ & & $\mathrm{X}$ & $\mathrm{X}$ & $X$ & & 127.39 & 0 & 0.123 \\
\hline & 2 & & & $\mathrm{X}$ & $X$ & $X$ & & 127.55 & 0.16 & 0.114 \\
\hline & 3 & $X$ & & $\mathrm{X}$ & $X$ & & & 127.94 & 0.56 & 0.093 \\
\hline & 4 & $\mathrm{X}$ & & & $\mathrm{X}$ & $\mathrm{X}$ & & 128.02 & 0.63 & 0.090 \\
\hline & 5 & & $\mathrm{X}$ & $\mathrm{X}$ & $\mathrm{X}$ & $X$ & & 128.88 & 1.49 & 0.058 \\
\hline \multirow[t]{5}{*}{ Woodpeckers } & 1 & $X$ & $\mathrm{X}$ & $\mathrm{X}$ & $\mathrm{X}$ & $X$ & & -30.50 & 0 & 0.157 \\
\hline & 2 & $X$ & & $\mathrm{X}$ & $X$ & $X$ & & -30.24 & 0.27 & 0.137 \\
\hline & 3 & & $\mathrm{X}$ & $\mathrm{X}$ & $\mathrm{X}$ & $\mathrm{X}$ & & -29.63 & 0.87 & 0.101 \\
\hline & 4 & $\mathrm{X}$ & $\mathrm{X}$ & & $\mathrm{X}$ & $\mathrm{X}$ & & -29.47 & 1.03 & 0.094 \\
\hline & 5 & $X$ & & & $X$ & $X$ & & -28.43 & 2.07 & 0.056 \\
\hline \multirow[t]{4}{*}{ All groups } & 1 & $\mathrm{X}$ & & $\mathrm{X}$ & $X$ & $\mathrm{X}$ & & 190.17 & 0 & 0.373 \\
\hline & 2 & $X$ & $\mathrm{X}$ & $\mathrm{X}$ & $X$ & $X$ & & 191.41 & 1.24 & 0.201 \\
\hline & 3 & $\mathrm{X}$ & & $\mathrm{X}$ & $X$ & $\mathrm{X}$ & $\mathrm{X}$ & 192.29 & 2.11 & 0.130 \\
\hline & 4 & $X$ & $\mathrm{X}$ & $\mathrm{X}$ & $\mathrm{X}$ & $X$ & $\mathrm{X}$ & 193.53 & 3.35 & 0.070 \\
\hline
\end{tabular}

473 Models are ranked by order of lowest AICc score and only models with a weight over 0.05 were

474 considered. Rank, explanatory variables, AICc score, delta AICc relative to the model with

475 lowest AICc score and Akaike weights are given for each individual model.

476

477

478

479

480

481

482

483 
484 Table 4. Summary outputs of Brazilian and international internet saliency model averages.

\begin{tabular}{|c|c|c|c|c|c|c|c|}
\hline \multirow[t]{2}{*}{ Group } & \multirow[t]{2}{*}{ Predictor } & \multicolumn{3}{|c|}{ Brazil internet saliency } & \multicolumn{3}{|c|}{ International internet saliency } \\
\hline & & Estimate & SE & $\omega \mathrm{AICc}$ & Estimate & $\mathrm{SE}$ & $\omega \mathrm{AICc}$ \\
\hline \multirow[t]{7}{*}{ Hummingbirds } & Intercept & 0.98 & 0.06 & - & 2.72 & 0.03 & - \\
\hline & RAN & -0.03 & 0.05 & 0.36 & 0.10 & 0.04 & 1.00 \\
\hline & POP & 0.43 & 0.06 & 1.00 & 0.04 & 0.04 & 0.72 \\
\hline & ANT & 0.25 & 0.11 & 1.00 & - & - & - \\
\hline & SIZ & 0.02 & 0.04 & 0.36 & 0.01 & 0.02 & 0.18 \\
\hline & EDM & 0.08 & 0.12 & 0.45 & -0.03 & 0.06 & 0.25 \\
\hline & EDG & - & - & - & - & - & - \\
\hline \multirow[t]{7}{*}{ Toucans } & Intercept & 1.02 & 0.10 & - & 2.79 & 0.08 & - \\
\hline & RAN & $<0.01$ & 0.03 & 0.07 & - & - & - \\
\hline & POP & 0.46 & 0.07 & 1.00 & 0.05 & 0.08 & 0.38 \\
\hline & ANT & 0.11 & 0.20 & 0.33 & 0.02 & 0.08 & 0.10 \\
\hline & $\mathrm{SIZ}$ & 0.20 & 0.11 & 0.88 & 0.32 & 0.09 & 1.00 \\
\hline & EDM & -0.04 & 0.15 & 0.14 & - & - & - \\
\hline & EDG & $<0.01$ & 0.05 & 0.07 & -0.08 & 0.17 & 0.29 \\
\hline \multirow[t]{7}{*}{ Parrots } & Intercept & 1.08 & 0.08 & - & 2.87 & 0.09 & - \\
\hline & RAN & 0.01 & 0.04 & 0.15 & 0.07 & 0.07 & 0.58 \\
\hline & POP & 0.42 & 0.07 & 1.00 & $<0.01$ & 0.03 & 0.47 \\
\hline & ANT & 0.03 & 0.09 & 0.26 & 0.20 & 0.15 & 0.56 \\
\hline & SIZ & 0.37 & 0.06 & 1.00 & 0.26 & 0.06 & 1.00 \\
\hline & EDM & 0.34 & 0.14 & 1.00 & -0.20 & 0.15 & 0.60 \\
\hline & EDG & 0.03 & 0.09 & 0.24 & - & - & - \\
\hline \multirow[t]{7}{*}{ Woodpeckers } & Intercept & 0.97 & 0.09 & - & 2.73 & 0.04 & - \\
\hline & RAN & 0.03 & 0.06 & 0.25 & 0.06 & 0.04 & 0.81 \\
\hline & POP & 0.37 & 0.08 & 1.00 & 0.04 & 0.04 & 0.65 \\
\hline & ANT & 0.36 & 0.14 & 1.00 & 0.07 & 0.06 & 0.73 \\
\hline & SIZ & 0.08 & 0.08 & 0.66 & 0.06 & 0.03 & 1.00 \\
\hline & EDM & -0.04 & 0.12 & 0.22 & -0.19 & 0.04 & 1.00 \\
\hline & EDG & $<-0.01$ & 0.07 & 0.09 & - & - & - \\
\hline \multirow[t]{7}{*}{ All groups } & Intercept & 1.00 & 0.04 & - & 2.76 & 0.03 & - \\
\hline & RAN & 0.01 & 0.03 & 0.29 & 0.09 & 0.03 & 1.00 \\
\hline & POP & 0.41 & 0.03 & 1.00 & 0.01 & 0.02 & 0.35 \\
\hline & ANT & 0.24 & 0.07 & 1.00 & 0.15 & 0.06 & 1.00 \\
\hline & SIZ & 0.22 & 0.03 & 1.00 & 0.17 & 0.02 & 1.00 \\
\hline & EDM & 0.23 & 0.08 & 1.00 & -0.16 & 0.06 & 1.00 \\
\hline & EDG & 0.05 & 0.09 & 0.42 & $<-0.01$ & 0.04 & 0.26 \\
\hline
\end{tabular}

485 Average parameter estimates and Akaike's weights ( $\omega$ AICc) of Brazilian and international 486 internet saliency models. Model averaging was carried out including only models with Akaike's 487 weight scores over 0.05 . 
490

491 Figures

492 Fig.1. Distribution of the log-transformed number of Brazilian and international webpages 493 mentioning species in each of the studied bird taxon.

494 Horizontal lines indicate median values, upper and lower box hinges represent first and third 495 quartiles, whiskers extend to 1.5 times the inter-quartile range, and dots represent values outside 496 this range.

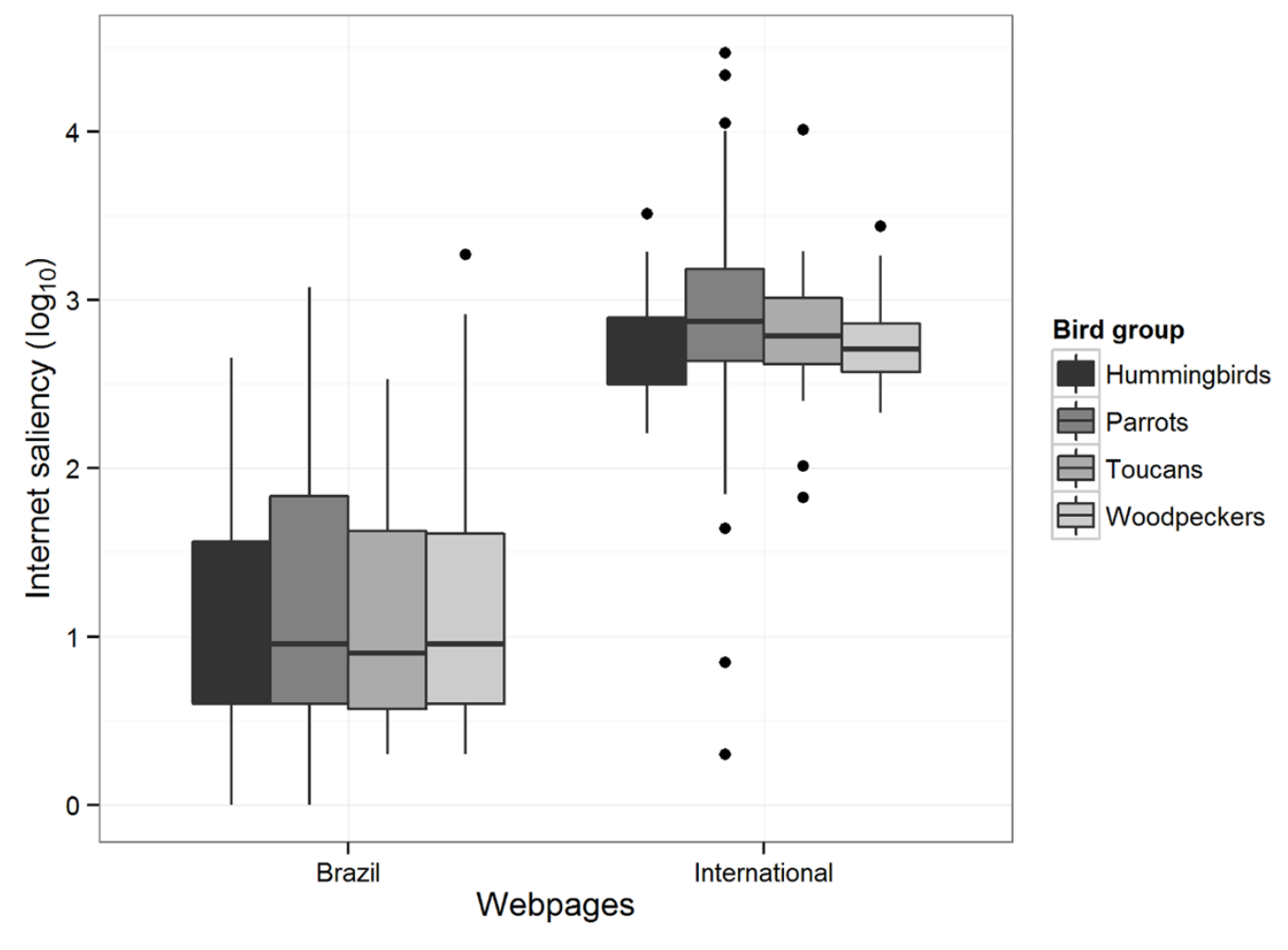

